Проблеми математичного моделювання та теорії диференціальних рівнянь

УДК $532.5+\mathbf{5 1 7 . 9 5 8}$

\title{
ПРО ВЗАЄМОДІЮ ПРОСТОРОВИХ ВИХОРІВ
} ІЗ РІЗНИМИ ІНТЕНСИВНІСТЮ І КРУТКОЮ

О. А. Мельник*, В. I. Перехрест**

* Національна металургійна академія України, Дніпропетровсък, 49005. E-mail: nmetau-melnik@mail.ru

** Дніпропетровсъкий національний університет ім. Олеся Гончара, Дніпропетровсък, 49050. E-mail: perekhrest@i.ua

Розглядається кінематична взаємодія паралельних просторових вихорів одного напрямку обертання з різними інтенсивностями та закручуванням, яка зумовлює зміщення їх центрів та об'єднання в один вихор. Показано, що результати взаємодії просторових вихорів суттєво відрізняються від результатів накладання плоских течій, породжених комплексними потенціалами джерел i вихроджерел.

Ключові слова: планетарний вихор, резонансні умови і траєкторії, утворення супутників планет.

\section{1. Вступ}

У праці [3] отримано та детально вивчено окремий розв'язок рівнянь Ейлера, який являє собою одиничний вихор-шнур у просторі. Це своєрідне вихроджерело є просторовим аналогом відповідних вихроджерел у плоскій задачі гідродинаміки $[1,2]$. Відомо [1], що при накладанні течій, породжених комплексними потенціалами типу джерел і вихроджерел, моделюються складні взаємодії вихорів та обтікання плоских тіл. При цьому центри складених джерел - особливі точки різних типів - при взаємодії не зміщуються. Таким чином конструюються відомі моделі вихрових ниток, вихрових ланцюжків, доріжок Кармана та ін. Нижче досліджуються моделі взаємодії просторових вихорів [3] із паралельними осями; показано, що при таких взаємодіях центри вихорів завжди зміщуються $[4,5]$, а у випадках одного напрямку закручування об'єднуються [4] при певних, «критичних» відстанях.

\section{2. Побудова моделі взаємодії двох вихорів}

Випишемо осесиметричне поле швидкостей одиничного вихрового шнура 3 віссю $\mathrm{Oz}$ у циліндричній системі координат $(r, \varphi, \mathrm{z})$ :

$$
\begin{gathered}
V_{y}^{(0)}=0 ; \quad V_{z}^{(0)}=A_{0}\left(1-\frac{y^{2}}{2}\right) \exp \left(-\frac{y^{2}}{2}\right) ; \\
V_{\varphi}^{(0)}=A_{0} y \exp \left(-\frac{y^{2}}{2}\right),
\end{gathered}
$$

(C) О. А. Мельник ${ }^{*}$, В. I. Перехрест ${ }^{* *}, 2011$ 
де $y=C_{0} r / 2$ - безрозмірна радіальна змінна, $A_{0}=C_{0}^{2} A / 4$ - константа, $C_{0}$, $A$ - довільні сталі, причому $C_{0}$ визначає інтенсивність закручування вихора і одночасно є масштабним множником радіальної безрозмірної координати $y$. Зі збільшенням цього параметра вихрове збурення-шнур стискується до осі одночасно із зростанням амплітуд швидкостей та його енергії. Течія $(2.1) €$ просторовим гвинтом, де поєднується суто вертикальний рух уздовж осі $\mathrm{Oz}$ зі швидкістю $A_{0}$ з чисто обертальним рухом циліндра $y=\sqrt{2}$ зі швидкістю $A_{0} / e$. Траєкторіями руху на проміжних циліндрах $є$ просторові гвинтові лінії зі змінним кроком. При цьому в області власне шнура $0 \leq y \leq \sqrt{2}$ течія є висхідною з витоком поля $Q_{z}=2 \pi A / e$ і не залежить від величини закручування $C_{0}$. Зовні шнура маємо низхідну течію з тим же витоком протилежного напрямку. Запишемо це поле, як у праці [5], у глобальній циліндричній системі координат, з початком координат, у якій вісь шнура (2.1) має координати ( $y_{0}$, $\left.\varphi_{0}\right)$.

У подальшому застосуємо формули переходу між місцевими координатами $(\bar{y}, \bar{\varphi})$ та глобальними координатами $(y, \varphi)$ довільної точки простору

$$
\begin{gathered}
\bar{y}^{2}=y_{0}^{2}-2 y_{0} y \cos \left(\varphi-\varphi_{0}\right)+y^{2}, \\
\sin \bar{\varphi}=\frac{y}{\bar{y}} \sin \left(\varphi-\varphi_{0}\right), \quad \cos \bar{\varphi}=\frac{1}{y}\left(y \cos \left(\varphi-\varphi_{0}\right)-y_{0}\right) .
\end{gathered}
$$

Перетворимо з допомогою (2.2) поле (2.1) до глобальних координат $(y, \varphi)$ :

$$
\begin{gathered}
V_{y}=-A_{0} y_{0} \sin \left(\varphi-\varphi_{0}\right) \exp \left(-\frac{1}{2} \bar{y}^{2}\right), \\
V_{z}=A_{0}\left(1-\frac{\bar{y}^{2}}{2}\right) \exp \left(-\frac{\bar{y}^{2}}{2}\right), \\
V_{\varphi}=A_{0}\left(y_{0} \cos \left(\varphi-\varphi_{0}\right)-y\right) \exp \left(-\frac{1}{2} \bar{y}^{2}\right) .
\end{gathered}
$$

Прямою підстановкою неважко перевірити, що рівняння нерозривності у глобальних координатах $[4,5]$ :

$$
\frac{\partial}{\partial y}\left(y V_{y}\right)+\frac{\partial}{\partial z}\left(y V_{z}\right)+\frac{\partial V_{\varphi}}{\partial \varphi}=0
$$

поле (2.3) задовольняе тотожно при будь-яких $y_{0}, \varphi_{0}$. Знайдемо функцію течії поля (2.3), переписавши це поле у вигляді диференціальних рівнянь руху в координатах $(y, \varphi, z)$ :

$$
\frac{d y}{d t}=V_{y}, \quad \frac{d z}{d t}=V_{z}, \quad y \frac{d \varphi}{d t}=V_{\varphi} .
$$

Комбінуючи ці рівняння, маємо наступне диференціальне рівняння у фазовій площині $(y, \varphi)$ :

$$
\frac{d y}{d \varphi}=y_{0} \frac{\sin \left(\varphi-\varphi_{0}\right)}{y\left(y_{0} \cos \left(\varphi-\varphi_{0}\right)-y\right)},
$$


або $\left[y\left(y_{0} \cos \left(\varphi-\varphi_{0}\right)-y\right)\right] d y-y_{0} \sin \left(\varphi-\varphi_{0}\right) d \varphi=0$. Останне рівняння за допомогою інтегрувального множника $\mu=\exp \left(-\frac{y_{0}^{2}+y^{2}}{2}\right)$ зводиться до рівняння у повних диференціалах і має інтеграл вигляду $\Psi(y, \varphi)=\Psi_{0}$, де

$$
\Psi=\exp \left(-\frac{y^{2}}{2}\right)
$$

Неважко встановити, що швидкості (2.3) виражаються через функцію течії (2.7) такими залежностями [1-3]: $V_{y}=\frac{1}{y} \frac{\partial \Psi}{\partial \varphi}, V_{\varphi}=-\frac{\partial \Psi}{\partial y}, V_{z}=V_{z}(y, \varphi)$. Поле тиску для одиничного вихрового шнура знайдено у праці [4] у формі безрозмірного тиску $P=p / p_{\infty}, P=1-q(y), q(y)=\chi^{2} \exp \left(-\bar{y}^{2} / 2\right)$, де $q(y)$ - безрозмірне падіння тиску, $p_{\infty}$ - тиск на нескінченності, $\chi=\frac{A C_{0}^{2}}{4 V_{0}}$, а $V_{0}=\sqrt{2 p_{\infty} / \rho}$ - швидкісний напір на нескінченності для даного середовища. Величину $\chi$ доцільно назвати узагальненим коефіцієнтом інтенсивності шнура.

\section{3. Дослідження взаємодії вихорів}

Переходячи до розгляду взаємодії двох паралельних вихрових шнурів одного напрямку обертання [5], для зручності розташуємо центри цих вихорів на однакову відстань $y_{0}$ від початку координат $y=0$ на променях $\varphi_{0}=0$ та $\varphi_{0}=\pi$. Для другого (правого) вихору (рис. 1 ) покладемо $\varphi_{0}=0$, тоді формули переходу координат (2.2) набудуть такого вигляду:

$$
\bar{y}^{2}=y_{0}^{2}-2 y_{0} y \cos \varphi+y^{2} .
$$

Щодо поля швидкостей (2.3), то з цих формул вилучимо параметр $\varphi_{0}$.

Для першого (лівого) вихору (рис. 1) покладемо $\varphi_{0}=\pi$ i врахуємо, що даний вихор має іншу закрутку та інтенсивність, ніж перший. Для цього введемо коефіцієнти відношення для інтенсивності $\alpha=\frac{A_{1}}{A}$ i $\kappa=\frac{C_{0,1}}{C_{0}}$ для закручування. Всі параметри першого вихору спочатку переведемо в реальні координати, а потім зведемо до безромірних координат другого вихору. Такі перетворення зведуть формулу (2.2) до вигляду: $\tilde{y}^{2}=\left(y_{0}^{2}+2 y_{0} y \cos \varphi+y^{2}\right) \kappa^{2}$, поле швидкостей (2.3) перетвориться до вигляду:

$$
\begin{gathered}
V_{y}^{(1)}=\tilde{A}_{0} y_{0} \sin \varphi \exp \left(-\frac{1}{2} \tilde{y}^{2}\right) \alpha \kappa^{3}, \\
V_{z}^{(1)}=\tilde{A}_{0}\left(1-\frac{\tilde{y}^{2}}{2}\right) \exp \left(-\frac{\tilde{y}^{2}}{2}\right) \alpha \kappa^{2}, \\
V_{\varphi}^{(1)}=\tilde{A}_{0}\left(y-y_{0} \cos \varphi\right) \exp \left(-\frac{1}{2} \tilde{y}^{2}\right) \alpha \kappa^{2},
\end{gathered}
$$

адже для першого вихору маємо: $\quad \tilde{A}_{0}=C_{0,1}^{2} A_{1} / 4=\alpha \kappa^{2} C_{0}^{2} A / 4=\alpha k^{2} A_{0}$, $\tilde{y}_{0}=\kappa y_{0}$. При накладанні полів швидкостей двох даних вихрових шнурів будуть складатися відповідні компоненти полів швидкостей обох вихорів:

$$
V_{y}^{(s)}=V_{y}^{(1)}+V_{y}^{(2)}, \quad V_{z}^{(s)}=V_{z}^{(1)}+V_{z}^{(2)}, \quad V_{\varphi}^{(s)}=V_{\varphi}^{(1)}+V_{\varphi}^{(2)} .
$$


Це невісесиметричне поле як сума полів типу (2.3) через лінійність рівняння нерозривності (2.4) буде тотожно його задовольняти, тобто кінематично сумарне поле (3.3) може існувати. Неважко бачити, що воно є неперервним в усьому просторі, оскільки при $y \rightarrow+\infty$ маємо [5]: $\lim _{y \rightarrow+\infty} V_{y}^{(s)}=\lim _{y \rightarrow+\infty} V_{\varphi}^{(s)}=$ $\lim _{y \rightarrow+\infty} V_{z}^{(s)}=0$. Функція течії даного поля (3.3) знаходиться також складанням функцій течії двох даних вихорів, і являє собою інтеграл вигляду

$$
\Psi=\alpha \kappa^{2} \exp \left(-\frac{\tilde{y}^{2}}{2}\right)+\exp \left(-\frac{\bar{y}^{2}}{2}\right) .
$$

Як ми бачимо, фактично функція течії сумарного поля (3.3) є сумою функцій течій кожного вихору, записана у спільних координатах $(y, \varphi)$. Швидкості (3.3) виражаються через функцію течії (3.4) такими залежностями:

$$
V_{y}^{(s)}=\frac{1}{y} \frac{\partial \Psi}{\partial \varphi}, \quad V_{\varphi}^{(s)}=-\frac{\partial \Psi}{\partial y}, \quad V_{z}^{(s)}=V_{z}^{(s)}(y, \varphi)
$$

в силу чого рівняння нерозривності (2.4) завжди задовольняється. Інтеграл (3.4) дає сім’ю циліндричних поверхонь течії з напрямними лініями (рис. 1). На рисунку 1 ліворуч знаходиться вихор зі зміненими параметрами, якому відповідає перша експонента з формули (3.4) i, відповідно, праворуч ми помістили вихор з параметрами $\alpha=1, k=1$. Надалі виконаємо дослідження взаємодії цих вихорів за допомогою просторового відображення ізоліній функції течії (3.4).

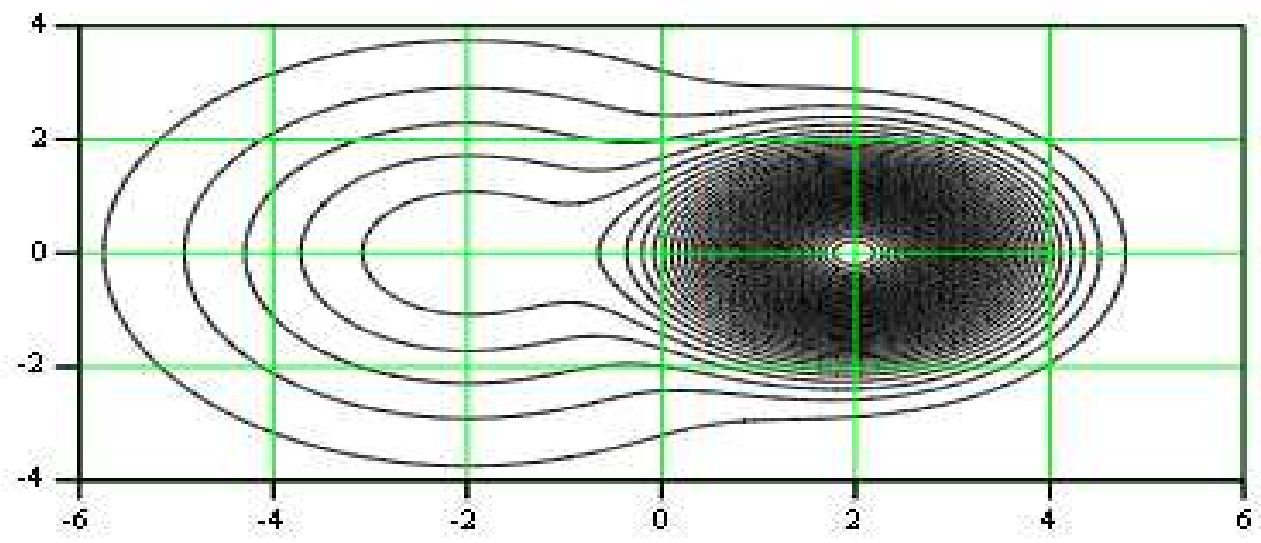

Рис. 1. Лінії течії

Рисунок 1 показує лінії течії двох взаємодіючих вихорів в площині $(y, \varphi)$, при $\alpha=1 / 2, \kappa=1 / 2, y_{0}=2\left(y_{1}=-1,9478, \quad y_{2}=1,9828, \quad y^{*}=-0,7882\right)$. 


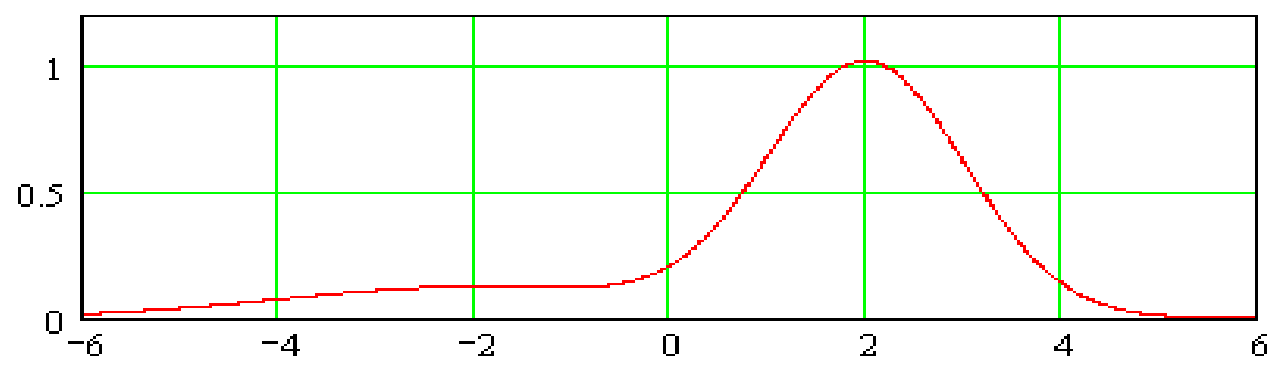

Рис. 2. Січна лінія

Рисунок 2 дає січну лінію поверхні функції течії, при $\alpha=1 / 2, \kappa=1 / 2$, $y_{0}=2\left(y_{1}=-1,9478, \quad y_{2}=1,9828, \quad y^{*}=-0,7882\right)$.

Щоб працювати в декартовій системі координат $\left(x_{1} ; y_{1}\right)$, було зроблено звичайний перехід від полярної $(y, \varphi):\left\{x_{1}=y \cos \varphi, \quad y_{1}=y \sin \varphi\right.$, причому фіксована точка $\left(y_{0}, \varphi_{0}\right)$ в декартовій системі координат буде мати наступні координати $\left(x_{01}=y_{0} \cos \varphi_{0}, y_{01}=y_{0} \sin \varphi_{0}\right)$ i, оскільки ми розташовуємо центри вихорів на одній лінії симетрично відносно початку координат, то для лівого вихору маємо $y_{01}=0, \varphi_{0}=\pi$, а для правого вихору маємо $y_{01}=0$, $\varphi_{0}=0$. Отже, функцію течії (3.4) отримаємо у вигляді:

$$
\Psi\left(x_{1}, y_{1}\right)=\alpha \kappa^{2} A_{0} \exp \left(-\frac{\tilde{y}^{2}}{2}\right)+A_{0} \exp \left(-\frac{\bar{y}^{2}}{2}\right)
$$

де $\quad \tilde{y}^{2}=\left(x_{01}^{2}+2 x_{01} x_{1}+x_{1}^{2}+y_{1}^{2}\right) \kappa^{2}, \quad \bar{y}^{2}=x_{01}^{2}-2 x_{01} x_{1}+x_{1}^{2}+y_{1}^{2}$.

Також для отримання осьового перерізу поверхні течії (див. рис. 2) достатньо в (3.6) покласти $y_{1}=0$ :

$$
\Psi\left(x_{1}, 0\right)=\alpha \kappa^{2} A_{0} \exp \left(-\frac{\tilde{y}^{2}}{2}\right)+A_{0} \exp \left(-\frac{\bar{y}^{2}}{2}\right),
$$

де $\quad \tilde{y}^{2}=\left(x_{01}^{2}+2 x_{01} x_{1}+x_{1}^{2}\right) \kappa^{2}, \quad \bar{y}^{2}=x_{01}^{2}-2 x_{01} x_{1}+x_{1}^{2}$.

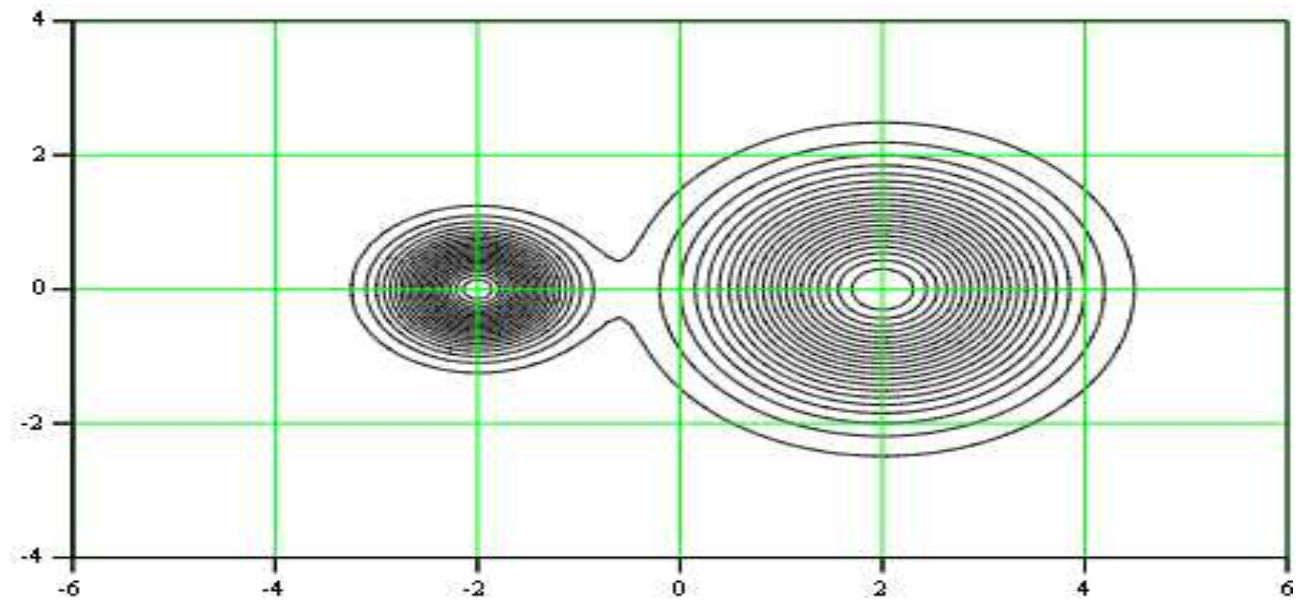

Рис. 3. Лінії течії 
Рисунок 3 показуе лінії течії двох взаємодіючих вихорів у площині $(y, \varphi)$, при $\alpha=1 / 4, \kappa=2, y_{0}=2\left(y_{1}=-1,9997, y_{2}=2,0, y^{*}=-0,5682\right)$.

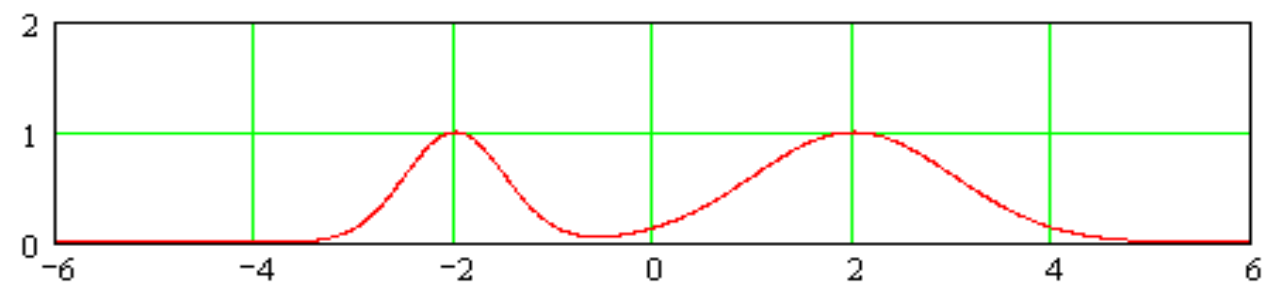

Рис. 4. Січна лінія

На рисунку 4 зображена січна лінія поверхні функції течії, при $\alpha=1 / 4$, $\kappa=2, y_{0}=2\left(y_{1}=-1,9478, \quad y_{2}=-1,9828, \quad y^{*}=-0,7882\right)$.

Згідно з рисунками 1 і 3 маємо три особливі точки, дві з яких є зміщеними центрами вихорів - точки типу центр і третя точка (вузлова) являє собою точку самоперетину сепаратриси, яка обходить навколо обох центрів. Цим точкам (див. рис. 2 і 4) відповідають два локальні максимуми і один локальний мінімум. Елементарні обчислення дозволяють скласти таблицю 1 критичних відстаней $y_{0}^{*}$, при яких відбувається злиття обох центрів 3 точкою самоперетину сепаратриси в точці $y^{*}$. Таблиця 2 містить ці ж критичні відстані $y_{0}^{*}$ при заміні амплітудного параметра $\alpha \rightarrow 1 / \alpha$ і параметра закручування $k \rightarrow 1 / k$.

\begin{tabular}{|c|c|c|c|}
\hline$\alpha$ & $\kappa$ & $y_{0}^{*}$ & $y^{*}$ \\
\hline 1 & 2 & 0,877 & 0,707 \\
1 & 3 & 0,670 & 0,570 \\
1 & 5 & 0,456 & 0,407 \\
3 & 1 & 1,422 & 1,010 \\
5 & 1 & 1,539 & 1,170 \\
7 & 1 & 1,609 & 1,260 \\
\hline
\end{tabular}

Таблиця 1.

\begin{tabular}{|c|c|c|c|}
\hline$\alpha$ & $\kappa$ & $y_{0}^{*}$ & $y^{*}$ \\
\hline $1 / 7$ & 1 & 1,609 & $-1,260$ \\
$1 / 5$ & 1 & 1,538 & $-1,170$ \\
$1 / 3$ & 1 & 1,422 & $-1,012$ \\
1 & $1 / 2$ & 1,754 & $-1,414$ \\
1 & $1 / 3$ & 2,010 & $-1,724$ \\
1 & $1 / 5$ & 2,280 & $-2,034$ \\
\hline
\end{tabular}

Таблиця 2.

\begin{tabular}{|c|c|c|c|c|c|c|c|c|}
\hline$y_{0}$ & 2,8 & 2,6 & 2,4 & 2,2 & 2,0 & 1,8 & 1,6 & 1,4 \\
\hline$y_{1}$ & $-2,8$ & $-2,5998$ & $-2,3985$ & $-2,1909$ & $-1,9478$ & & & \\
\hline$y^{*}$ & $-0,1842$ & $-0,3567$ & $-0,5535$ & $-0,7882$ & $-1,0993$ & & & \\
\hline$y_{2}$ & 2,7965 & 2,5944 & 2,3915 & 2,1876 & 1,9828 & 1,7774 & 1,5718 & 1,3668 \\
\hline
\end{tabular}




\begin{tabular}{|l|c|c|c|c|c|c|c|c|}
\hline$y_{0}$ & 2,8 & 2,6 & 2,4 & 2,2 & 2,0 & 1,8 & 1,6 & 1,4 \\
\hline$y_{1}$ & $-2,8$ & $-2,6$ & $-2,3992$ & $-2,1955$ & $-1,9765$ & $-1,6608$ & & \\
\hline$y^{*}$ & 0,0606 & $-0,0944$ & $-0,2705$ & $-0,4775$ & $-0,7369$ & $-1,1393$ & & \\
\hline$y_{2}$ & 2,7929 & 2,5888 & 2,3829 & 2,175 & 1,9653 & 1,7542 & 1,5428 & 1,3327 \\
\hline
\end{tabular}

Таблиця 4. $\alpha=1, \kappa=1 / 2$

Порівнюючи таблиці 4 і 3, а також 6 і 7, бачимо, що при однакових інтенсивностях на досить великих відстанях вихори не зазнають жодного зміщення центрів, але при поступовому наближенні центрів, більшого зміщення зазнає вихор, у якого більша закрутка. Також із таблиць 3,4 та формули (3.4) бачимо, що зменшення закрутки, тобто зменшення $k$, майже так само гасить сам вихор і його вплив на інший вихор, як зменшення інтенсивності, тобто в деякому сенсі $\kappa^{2} \approx \alpha$.

\begin{tabular}{|c|c|c|c|c|c|c|c|c|}
\hline$y_{0}$ & 2,8 & 2,6 & 2,4 & 2,2 & 2,0 & 1,8 & 1,6 & 1,4 \\
\hline$y_{1}$ & $-2,7995$ & $-2,5955$ & $-2,365$ & & & & & \\
\hline$y^{*}$ & $-1,0097$ & $-1,2881$ & $-1,6238$ & & & & & \\
\hline$y_{2}$ & 2,7952 & 2,5951 & 2,3952 & 2,1952 & 1,9954 & 1,7956 & 1,5958 & 1,3961 \\
\hline
\end{tabular}

Таблиця 5. $\alpha=1, \kappa=1 / 5$

\begin{tabular}{|c|c|c|c|c|c|c|c|c|}
\hline$y_{0}$ & 2,8 & 2,6 & 2,4 & 2,2 & 2,0 & 1,8 & 1,6 & 1,4 \\
\hline$y_{1}$ & $-2,80$ & $-2,60$ & $-2,4$ & $-2,1992$ & $-1,9959$ & $-1,7824$ & $-1,5297$ & \\
\hline$y^{*}$ & $-0,2249$ & $-0,2481$ & $-0,2772$ & $-0,3153$ & $-0,3676$ & $-0,4456$ & $-0,5812$ & \\
\hline$y_{2}$ & 2,8 & 2,6 & 2,4 & 2,2 & 1,9996 & 1,7981 & 1,5935 & 1,3806 \\
\hline
\end{tabular}

Таблиця 6. $\alpha=1 / 3, \kappa=1$

\begin{tabular}{|c|c|c|c|c|c|c|c|c|}
\hline$y_{0}$ & 2,8 & 2,6 & 2,4 & 2,2 & 2,0 & 1,8 & 1,6 & 1,4 \\
\hline$y_{1}$ & $-2,8$ & $-2,6$ & $-2,3997$ & $-2,1981$ & $-1,9903$ & $-1,7551$ & & \\
\hline$y^{*}$ & $-0,3987$ & $-0,4399$ & $-0,4921$ & $-0,5607$ & $-0,6571$ & $-0,8097$ & & \\
\hline$y_{2}$ & 2,8 & 2,6 & 2,4 & 2,2 & 1,998 & 1,7992 & 1,5972 & 1,392 \\
\hline
\end{tabular}

Таблиця 7. $\alpha=1 / 7, \kappa=1$

\section{4. Висновки}

Характеризуючи взаємний вплив такого роду вихорів, можна сказати, що дані вихори притягуються тим сильніше, чим більша закрутка обох вихорів, і чим ближче розташовані один до одного їх фактичні осьові центри. Так, 
iз таблиці 1 маємо, що із збільшенням закручування лише одного з вихорів у 3, 5, 7 разів критична відстань об'єднання зростає від 1,4 до 1,6 . У разі дуже різних закруток більш закручений і сконцентрований вихор ніби проникає у широке поле дії другого вихору, наближається до його центра і потім об’єднується з ним у точці $y^{*}$ (рис. 1,3 ). Також слід зазначити, що в кожному конкретному випадку є своє критичне значення $y_{0}$, при якому відбувається об'єднання точки перетину сепаратриси з центром одного із вихорів, після цього критичного $y_{0}$ той вихор, центр якого залишився, сам по собі поглинає іншого, за умови зменшення значення $y_{0}$. Ця особливість взаємодії просторових вихорів принципово відрізняється від взаємодій плоских вихроджерел, центри яких при взаємодії не зміщуються.

Також зазначимо, що у силу симетрії в площині $(y, \varphi)$ рух центрів вихорів відбувається по лінії їх початкового положення - саме по цій лінії ми зробили переріз (рис. 2,4 ) функції течії $(3.4)$, щоб виконати необхідні числові розрахунки. Центрам вихорів $y_{1}, y_{2}$ відповідають максимуми на цій лінії, а сідловій точці $y^{*}$ перетину сепаратриси - точка мінімуму. Розрахунки були зроблені у середовищі MathCad.

Аналіз даних таблиць 1,2 показує, що критичні відстані $y_{0}^{*}$ та точка об'єднання вихорів $y^{*}$ за параметрами $\alpha$ і $(1 / \alpha)$ симетричні відносно нуля це $\epsilon$ наслідком лінійної залежності інтенсивності вихорів від цього параметра. Для параметра $k$ такої симетрії не існує, бо параметр $k$ входить у формули, що описують взаємодію, у квадратичній та експоненційній залежностях.

\section{Бібліографічні посилання}

1. Васильев О. Ф. Основы механики винтовых и циркуляционных потоков / О. Ф. Васильев. М.-Л. : Госэнергоиздат, 1958. - 144 с.

2. Милн-Томсон. Теоретическая гидродинамика / Милн-Томсон. М. : Мир, 1964. $655 \mathrm{c}$.

3. Перехрест B. I. Просторовий циліндричний вихровий шнур як точний розв'язок рівнянь Ейлера / В. І. Перехрест// Вісник ДНУ, Сер. Механіка, 2003. - Т. 1, № $7 .-$ C. 46-53.

4. Перехрест B. I. Кінематика взаємодії двох паралельних вихрових шнурів одного напрямку обертання та інтенсивності / В. І. Перехрест, О. А. Мельник// Диференціальні рівняння та їх застосування: Зб. наук. пр. ДДУ. Дніпропетровськ, 2003. - C. 141-148.

5. Перехрест В. I. Про взаємодію просторових вихорів/ В. I. Перехрест, О. А. Мельник (у друку). 